\title{
Human Trefoil Factor 1-Secreting Lactococcus lactis AG013
}

National Cancer Institute

\section{Source}

National Cancer Institute. Human Trefoil Factor 1-Secreting Lactococcus lactis AG013.

NCl Thesaurus. Code C84842.

An oral rinse solution containing a strain of the bacteria Lactococcus lactis (L. lactis) genetically modified to express human T refoil Factor 1 (hTFF1) with potential cytoprotective activity. With oral rinsing, human trefoil factor 1 -secreting Lactococcus lactis AG013 may secrete and deliver hTFF1 to oral mucosal tissue, protecting or promoting the healing of damaged oral mucosa. hTFF1, a peptide belong ing to the Trefoil factors family (TFF), is normally secreted by mucous epithelia and is involved in protecting mucosal tissue and maintaining mucosal surface integ rity. 